\title{
Anion-mediated Architecture and Photochromism of Rigid Bipyridinium-based Coordination Polymers
}

\author{
Jian-Jun Liu, + Ying-Fang Guan, + Mei-Jin Lin, ${ }^{*}+\neq$ Chang-Cang Huang* + and Wen-Xin \\ Dait \\ +College of Chemistry, Fuzhou University, China, 350116; Email: \\ meijin_lin@fzu.edu.cn, cchuang@fzu.edu.cn,Tel: 008659122866143 \\ FState Key Laboratory of Structural Chemistry, Fujian Institute of Research on the \\ Structure of Matter, CAS, China, 350002.
}




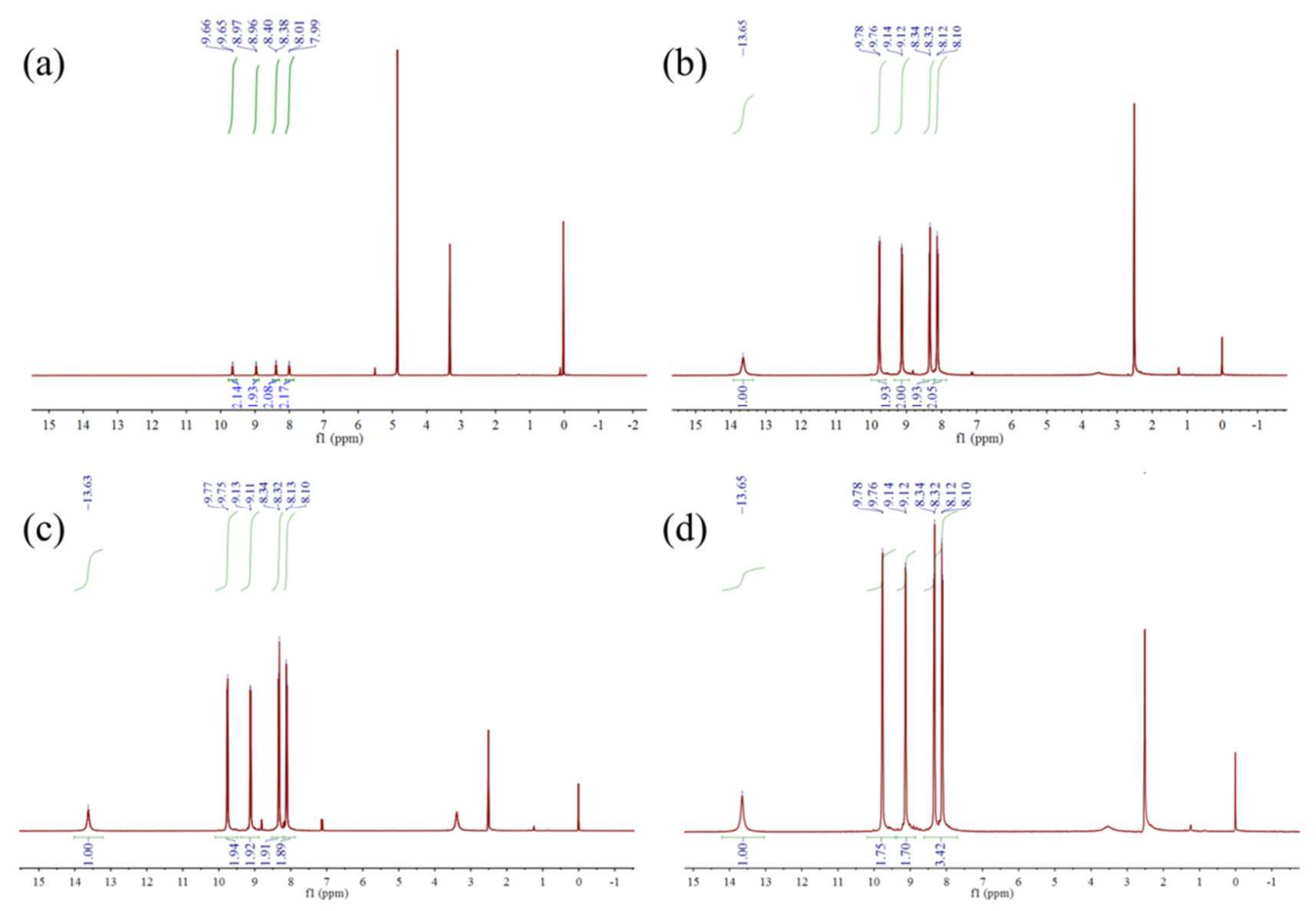

Figure S1. ${ }^{1} \mathrm{H}$ NMR spectra of (a) $\mathrm{H}_{2} \mathrm{bcbp} \cdot 2 \mathrm{Cl}$, (b) $\mathrm{H}_{2} \mathrm{bcbp} \cdot 2 \mathrm{PF}_{6}$, (c) $\mathrm{H}_{2} \mathrm{bcbp} \cdot 2 \mathrm{ClO}_{4}$ and (d) $\mathrm{H}_{2}$ bcbp $\cdot \mathrm{PO}_{3} \mathrm{~F}\left(400 \mathrm{MHz}, \mathrm{H}_{2}\right.$ bcbp $\cdot 2 \mathrm{PF}_{6}, \mathrm{H}_{2} \mathrm{bcbp} \cdot 2 \mathrm{ClO}_{4}$ and $\mathrm{H}_{2} \mathrm{bcbp} \cdot \mathrm{PO}_{3} \mathrm{~F}$ in $\mathrm{d}_{6}$-DMSO; $\mathrm{H}_{2} \mathrm{bcbp} \cdot 2 \mathrm{Cl}$ in $\mathrm{D}_{2} \mathrm{O}$ ).

?ִ

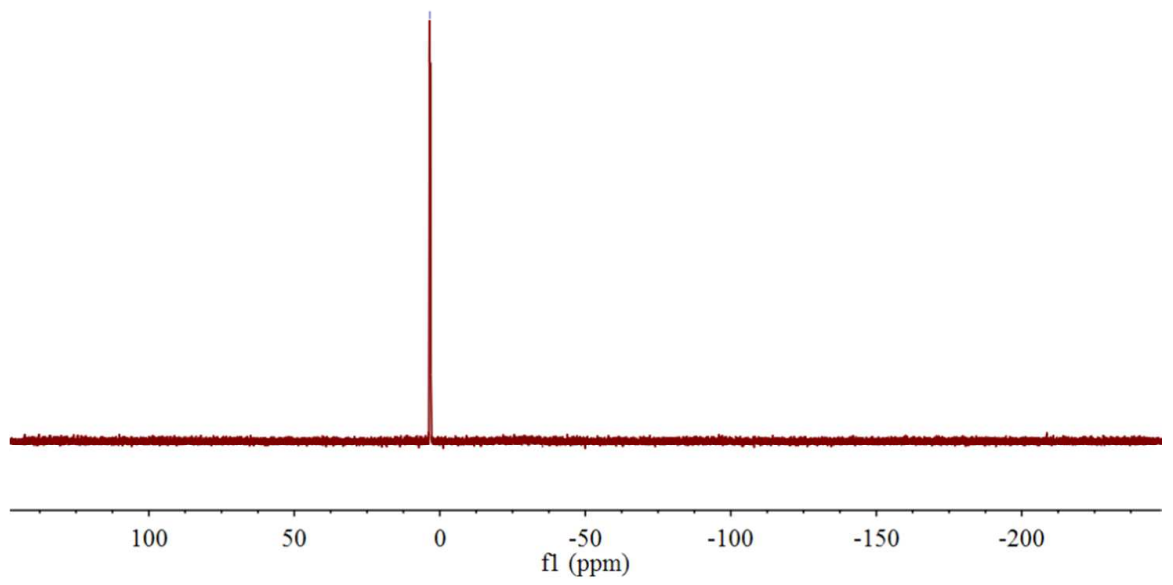

Figure S2. ${ }^{31} \mathrm{P}$ NMR spectrum of $\mathrm{H}_{2} \mathrm{bcbp} \cdot \mathrm{PO}_{3} \mathrm{~F}$. 


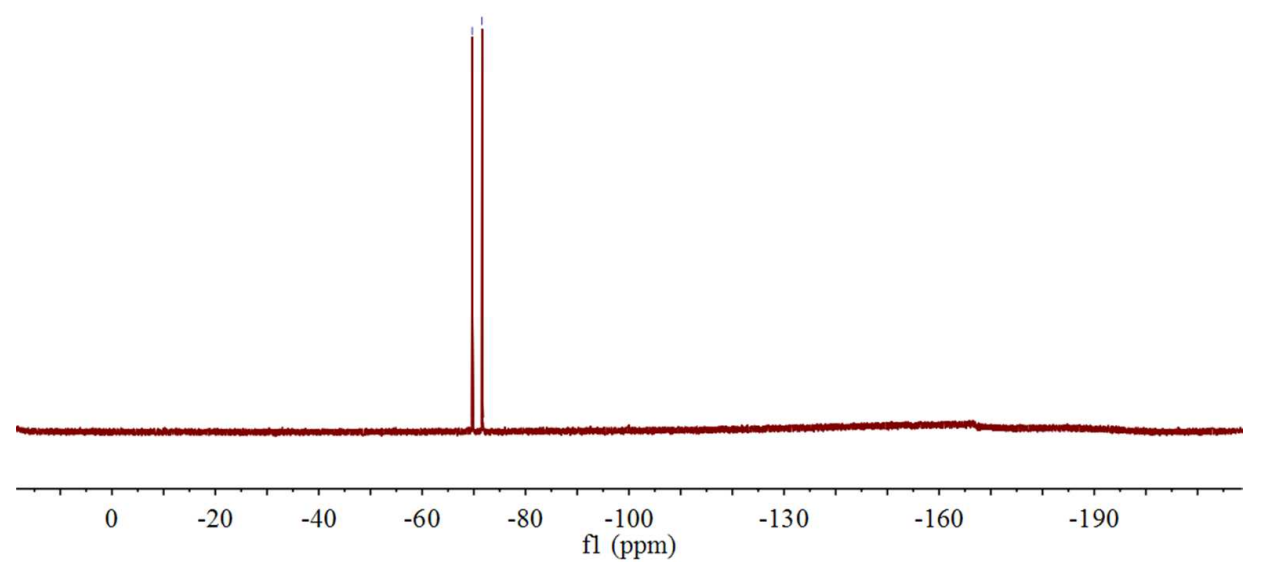

Figure S3. ${ }^{19} \mathrm{~F}$ NMR spectrum of $\mathrm{H}_{2} \mathrm{bcbp} \cdot \mathrm{PO}_{3} \mathrm{~F}$.

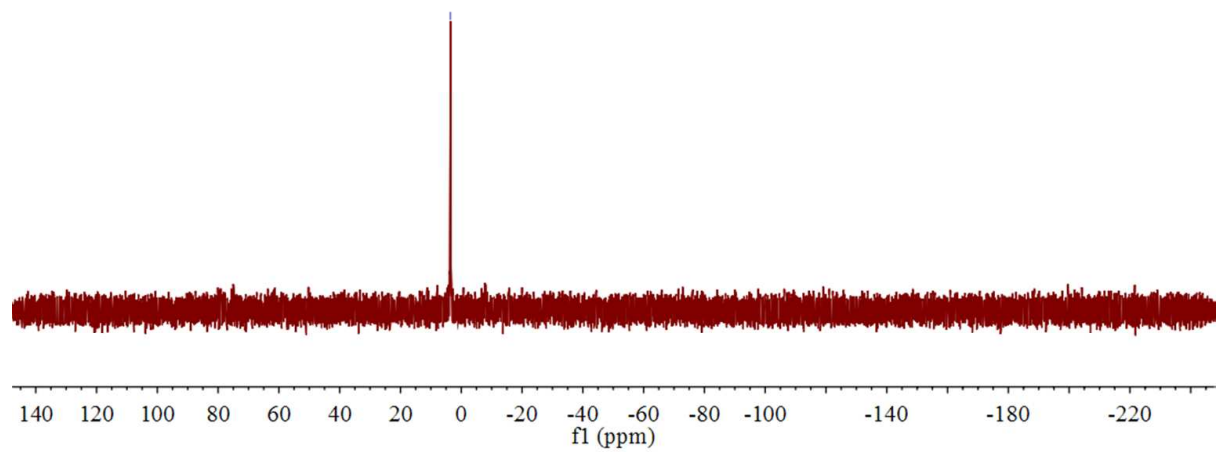

Figure S4. ${ }^{31} \mathrm{P}$ NMR spectrum of digested sample of $\mathbf{2}$. 


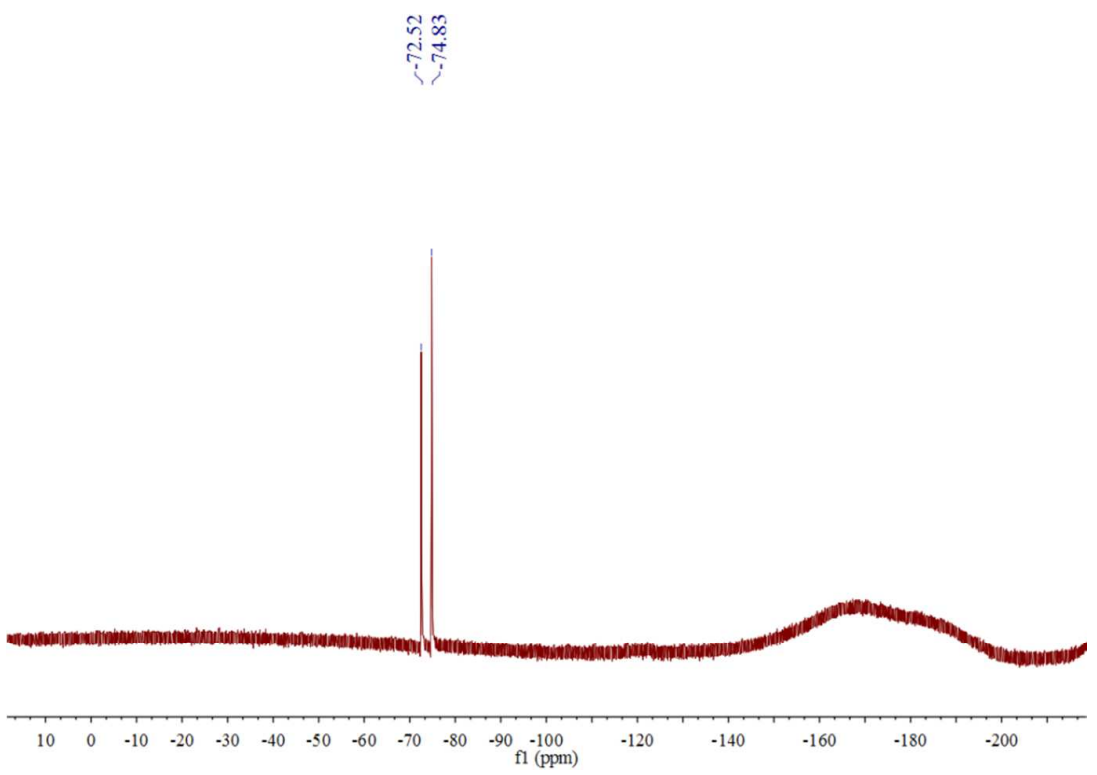

Figure S5. ${ }^{19} \mathrm{~F}$ NMR spectrum of digested sample of $\mathbf{2}$.

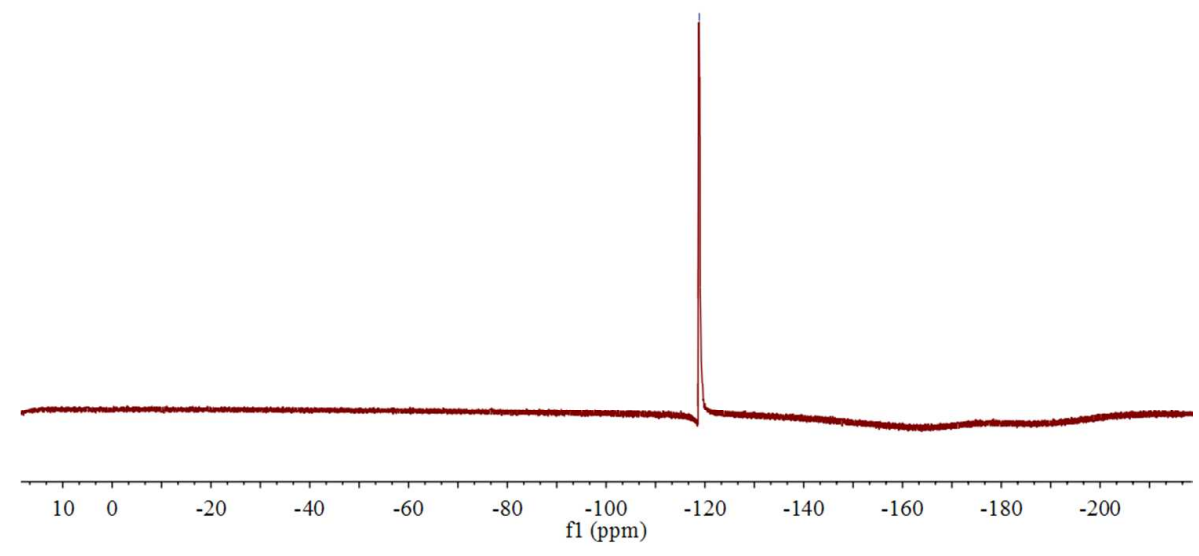

Figure S6. ${ }^{19} \mathrm{~F}$ NMR spectrum of digested sample of $\mathbf{4}$. 


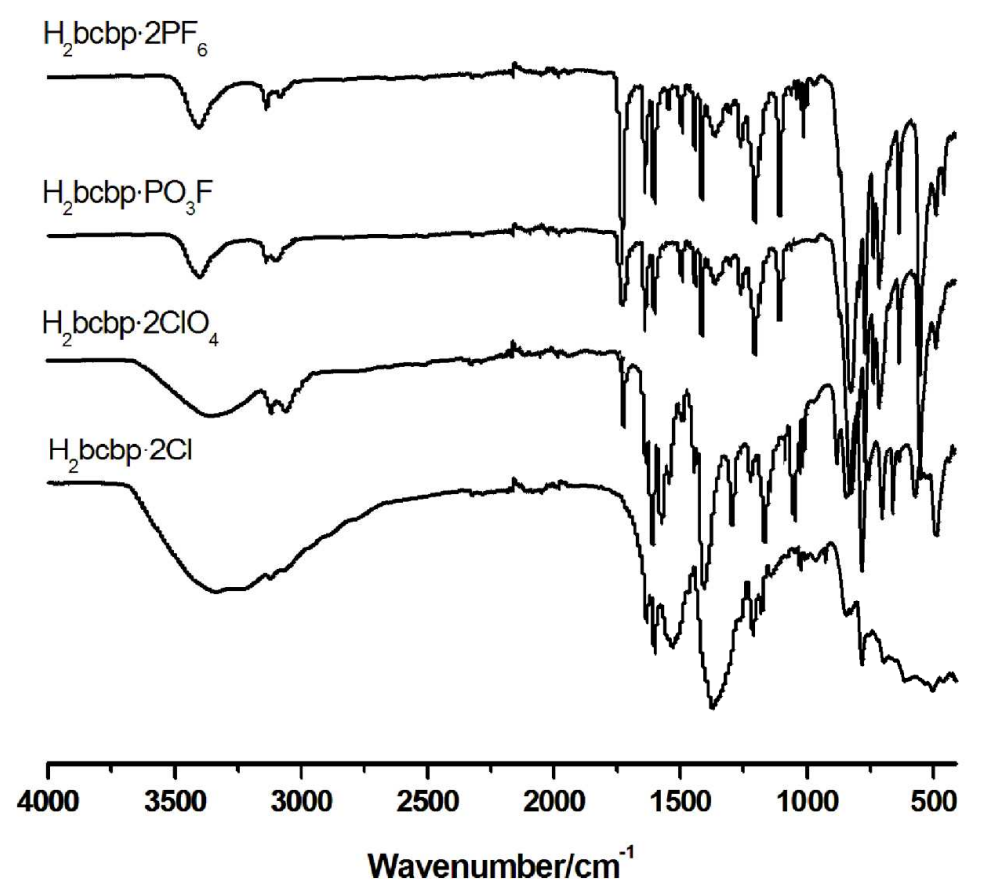

Figure S7. The IR spectra of ligand $\mathrm{H}_{2} \mathrm{bcbp} \cdot 2 \mathrm{PF}_{6}, \mathrm{H}_{2} \mathrm{bcbp} \cdot \mathrm{PO}_{3} \mathrm{~F}, \mathrm{H}_{2} \mathrm{bcbp} \cdot 2 \mathrm{ClO}_{4}$ and $\mathrm{H}_{2} \mathrm{bcbp} \cdot 2 \mathrm{Cl}$.

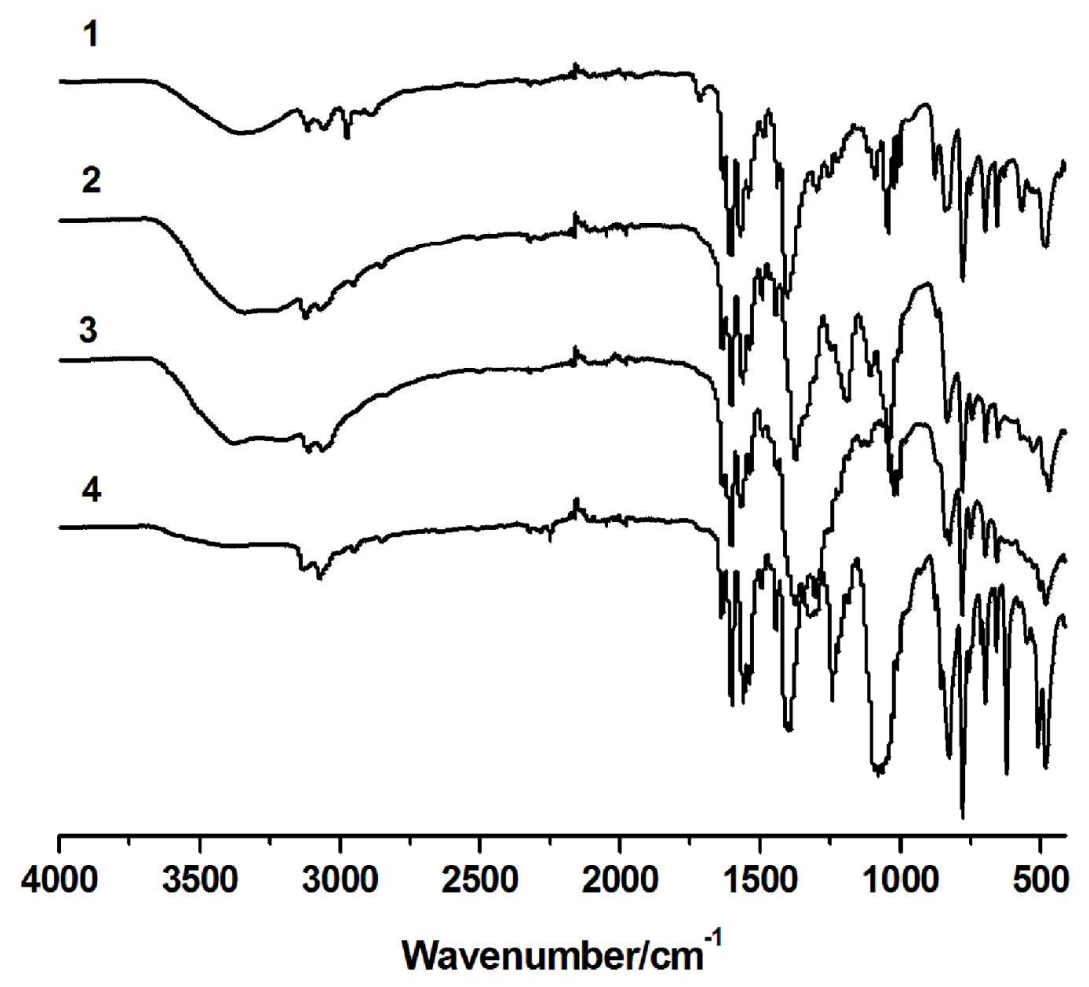

Figure S8. The IR spectra of 1-4 


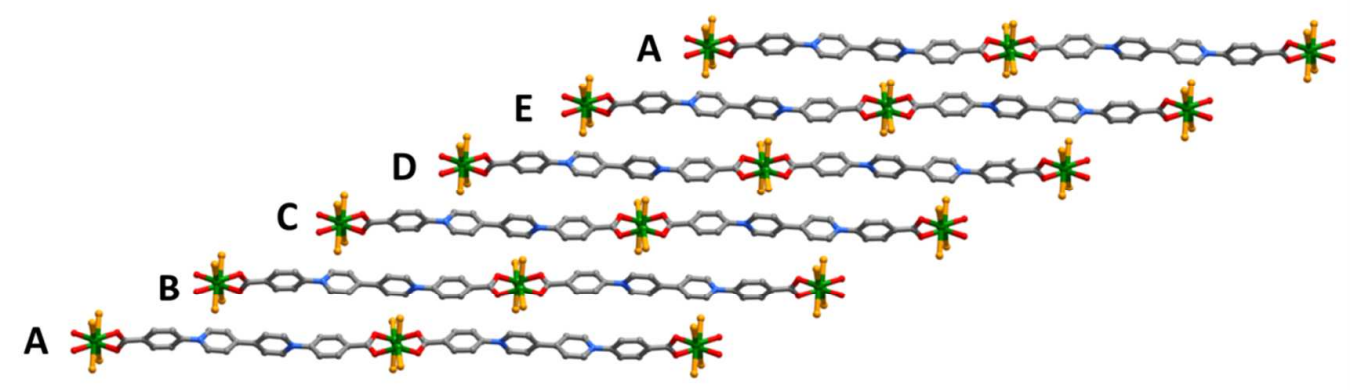

Figure S9. The $1 D$ chains aligned in $-A B C D E-$ mode within the ac plane

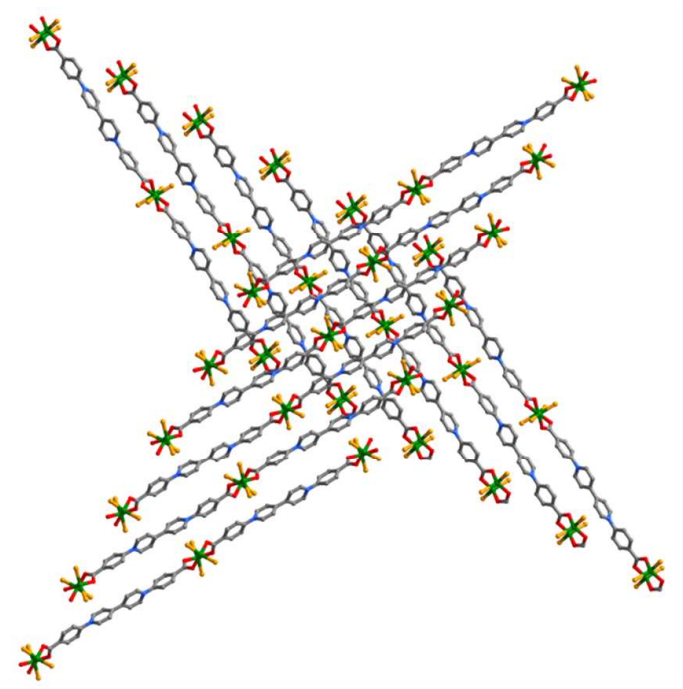

Figure S10. The 2D layers arranged in $-A B-$ stacking mode along the $b$ axis.

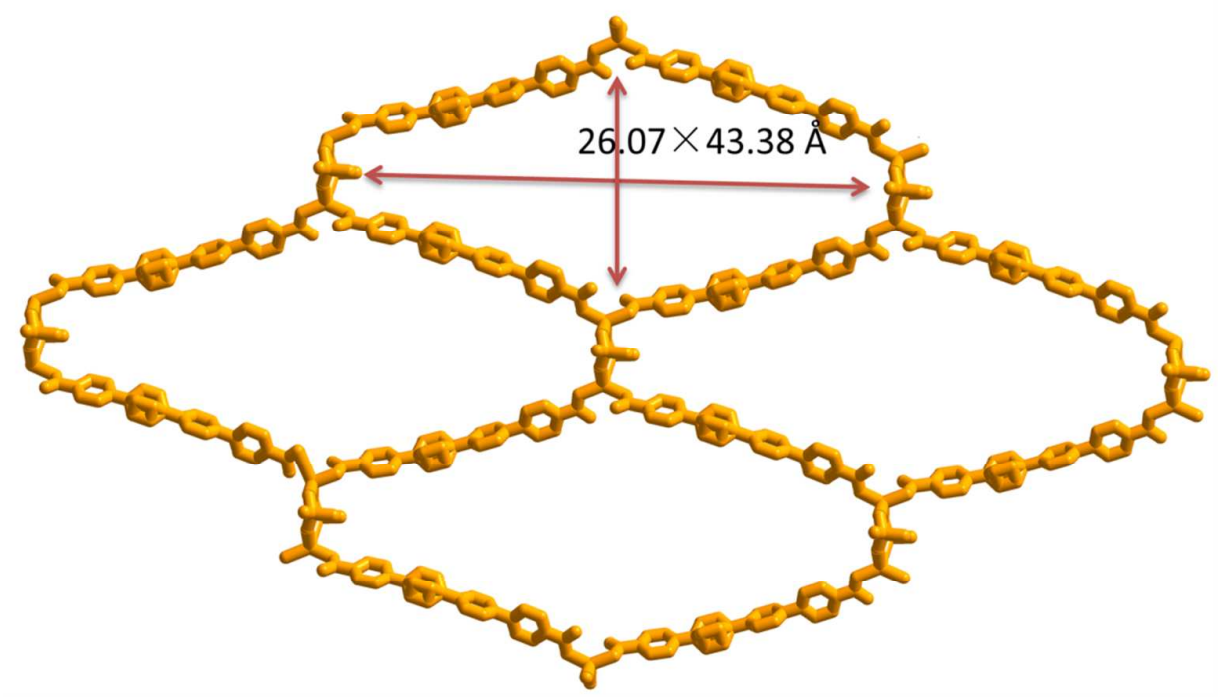

Figure S11. The 2D laminar networks of 2 with rhombus holes in the bc plane. 


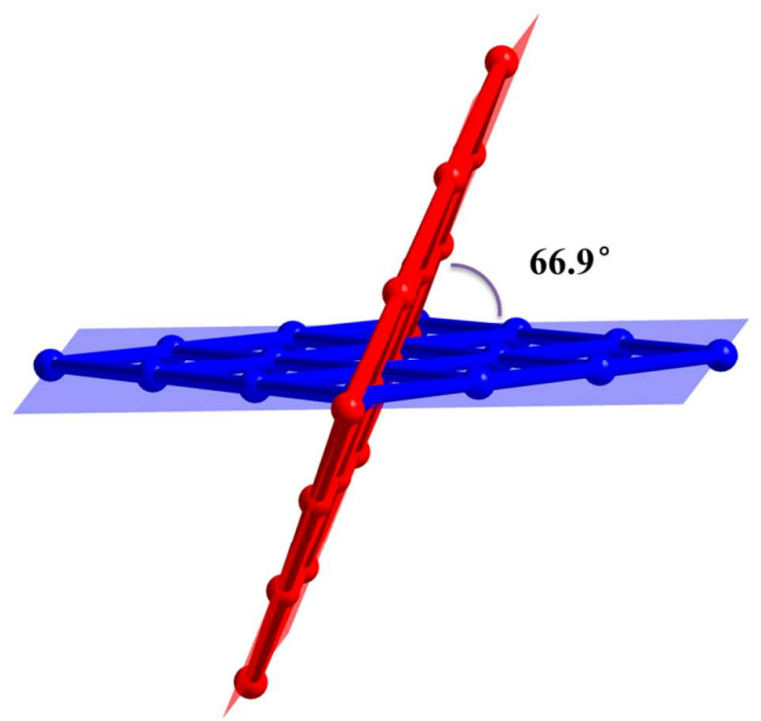

Figure S12. 2D + 2D $\rightarrow$ 3D inclined polycatenation motif of 2 , with the angle of $66.9^{\circ}$ between two members of different layer sets.

(a)

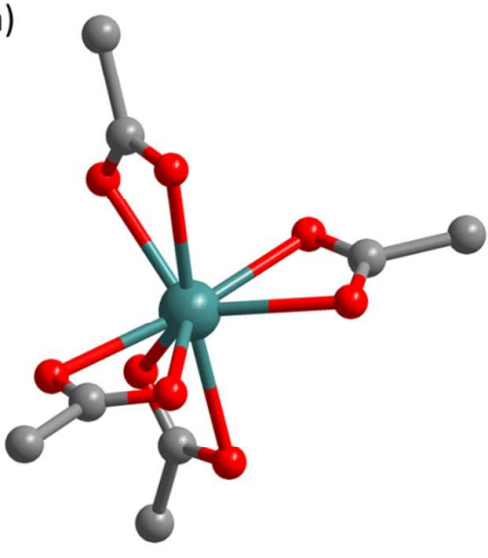

(b)

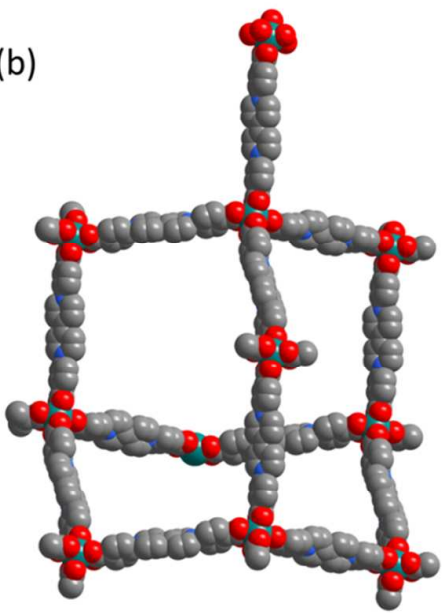

Figure S13. (a) The Cd-centered tetrahedral node of 4. (b) space-filling representation of the huge extended adamantane cage of 4. 

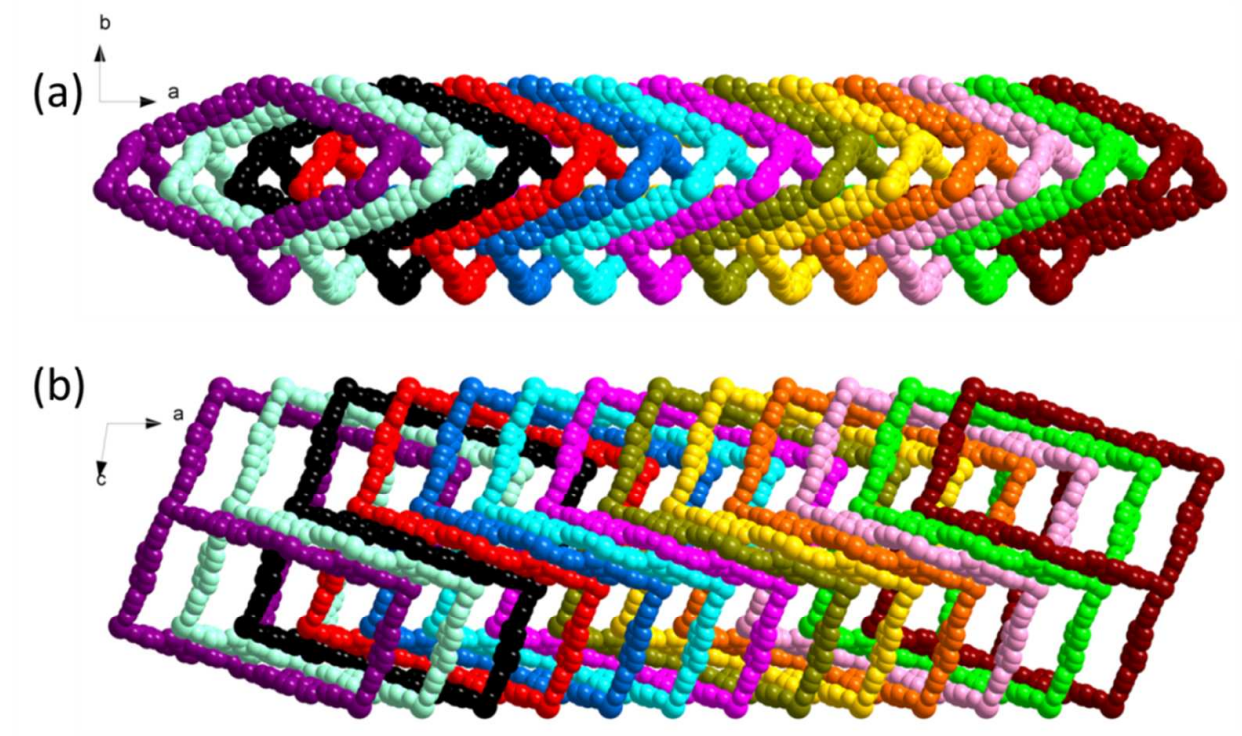

Figure S14. (a) View of the 13-fold interpenetrated huge-diamond framework of 4 along the $c$ axis; (b) view along $b$ axis.

Table S1. Crystal data and structure refinement for compounds 1-4

\begin{tabular}{|c|c|c|c|c|}
\hline Complex & 1 & 2 & 3 & 4 \\
\hline empirical Formula & $\mathrm{C}_{12} \mathrm{H}_{8} \mathrm{Cl}_{2} \mathrm{NO}_{2} \mathrm{Zn}$ & $\mathrm{C}_{24} \mathrm{H}_{16} \mathrm{FN}_{2} \mathrm{O}_{7} \mathrm{PZn}$ & $\mathrm{C}_{48} \mathrm{H}_{33} \mathrm{CdCl}_{3} \mathrm{~N}_{4} \mathrm{O}_{16}$ & $\mathrm{C}_{96} \mathrm{H}_{64} \mathrm{Cd}_{2} \mathrm{ClF}_{3} \mathrm{~N}_{8} \mathrm{O}_{20}$ \\
\hline formula weight & 334.46 & 559.73 & 1140.53 & 1966.80 \\
\hline crystal system & monoclinic & orthorhombic & monoclinic & monoclinic \\
\hline space group & $P 2 / c$ & Ibca & $P 2_{1} / c$ & $C 2 / c$ \\
\hline$a(\AA)$ & $10.253(2)$ & $14.390(3)$ & $10.969(2)$ & $10.941(2)$ \\
\hline$b(\AA)$ & $12.900(3)$ & $21.747(4)$ & $31.450(6)$ & $33.973(7)$ \\
\hline$c(\AA)$ & $20.009(4)$ & $43.383(9)$ & $14.914(3)$ & $14.014(3)$ \\
\hline$\alpha$ (deg) & 90 & 90 & 90 & 90 \\
\hline$B$ (deg) & $90.94(3)$ & 90 & $96.79(3)$ & $98.89(3)$ \\
\hline$\gamma(\mathrm{deg})$ & 90 & 90 & 90 & 90 \\
\hline$V\left(\AA^{3}\right)$ & $2646.1(9)$ & $13576(5)$ & $5108.5(18)$ & $5146.3(18)$ \\
\hline$z$ & 8 & 16 & 4 & 2 \\
\hline$T(\mathrm{~K})$ & $293(2)$ & $293(2)$ & $293(2)$ & $293(2)$ \\
\hline$\rho_{\text {calc }}\left(\mathrm{g} / \mathrm{cm}^{3}\right)$ & 1.679 & 1.095 & 1.483 & 1.269 \\
\hline$\mu(\mathrm{Mo} \mathrm{K} \alpha)\left(\mathrm{mm}^{-1}\right)$ & 2.250 & 0.810 & 0.657 & 0.511 \\
\hline$F(000)$ & 1336 & 4544 & 2304 & 1992 \\
\hline collected reflections & 21954 & 54622 & 46833 & 24977 \\
\hline unique reflections & 6062 & 7768 & 11652 & 5930 \\
\hline no. of observations & 5519 & 6734 & 8419 & 4918 \\
\hline goodness-of-fit on $\mathrm{F}^{2}$ & 1.187 & 1.050 & 1.100 & 1.100 \\
\hline$R_{1}{ }^{\mathrm{a}}, w R_{2}^{\mathrm{b}}(1>2 \sigma(\mathrm{I}))$ & $0.0562,0.1070$ & $0.1031,0.2775$ & $0.0481,0.1082$ & $0.0771,0.2183$ \\
\hline$R_{1}{ }^{\mathrm{a}}, w R_{2}^{\mathrm{b}}$ (all data) & $0.0648,0.1107$ & $0.1126,0.2852$ & $0.0709,0.1167$ & $0.0908,0.2342$ \\
\hline
\end{tabular}



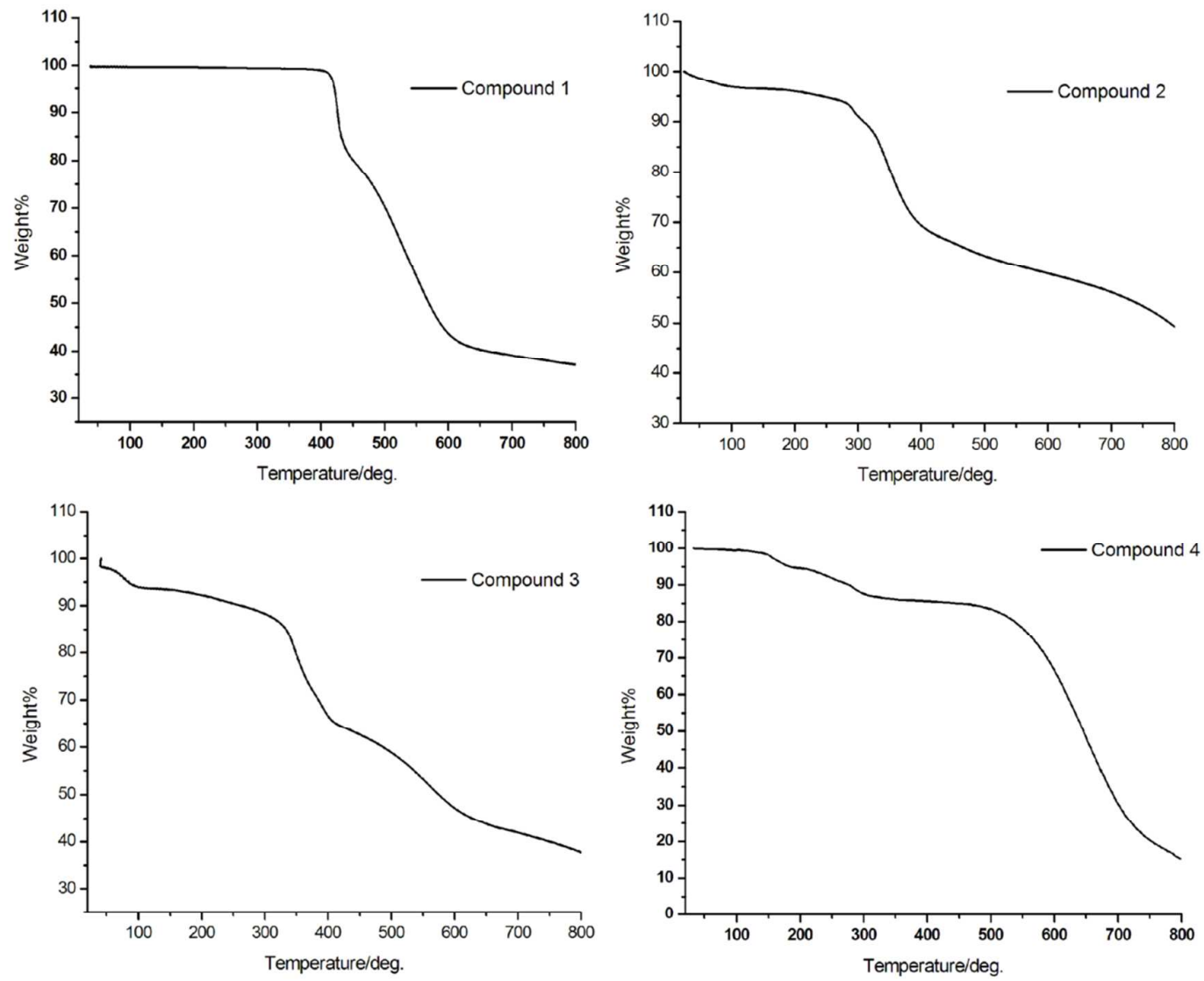

Figure S15. Thermogravimetric analyses of compounds 1-4. For compound 1, no obvious weight loss is observed before $400{ }^{\circ} \mathrm{C}$, which indicated that 1 has excellent thermal stability. For 2 , the weight loss of $6.36 \%$ from 28 to $120{ }^{\circ} \mathrm{C}$ is assigned to the removal of free solvents molecules (calcd $8.53 \%$ ). The complex starts to decompose after $250{ }^{\circ} \mathrm{C}$. A weight loss of $7.28 \%$ is observed for 3 in the temperature range of $30-100{ }^{\circ} \mathrm{C}$, which is attributed to the loss of solvents molecules (calcd $8.20 \%$ ), and the complex begins to decompose at $200{ }^{\circ} \mathrm{C}$. The TGA curve of 4 reveals almost no weight loss is observed from 30 to $150{ }^{\circ} \mathrm{C}$, and the complex begins to decompose at $180^{\circ} \mathrm{C}$. 

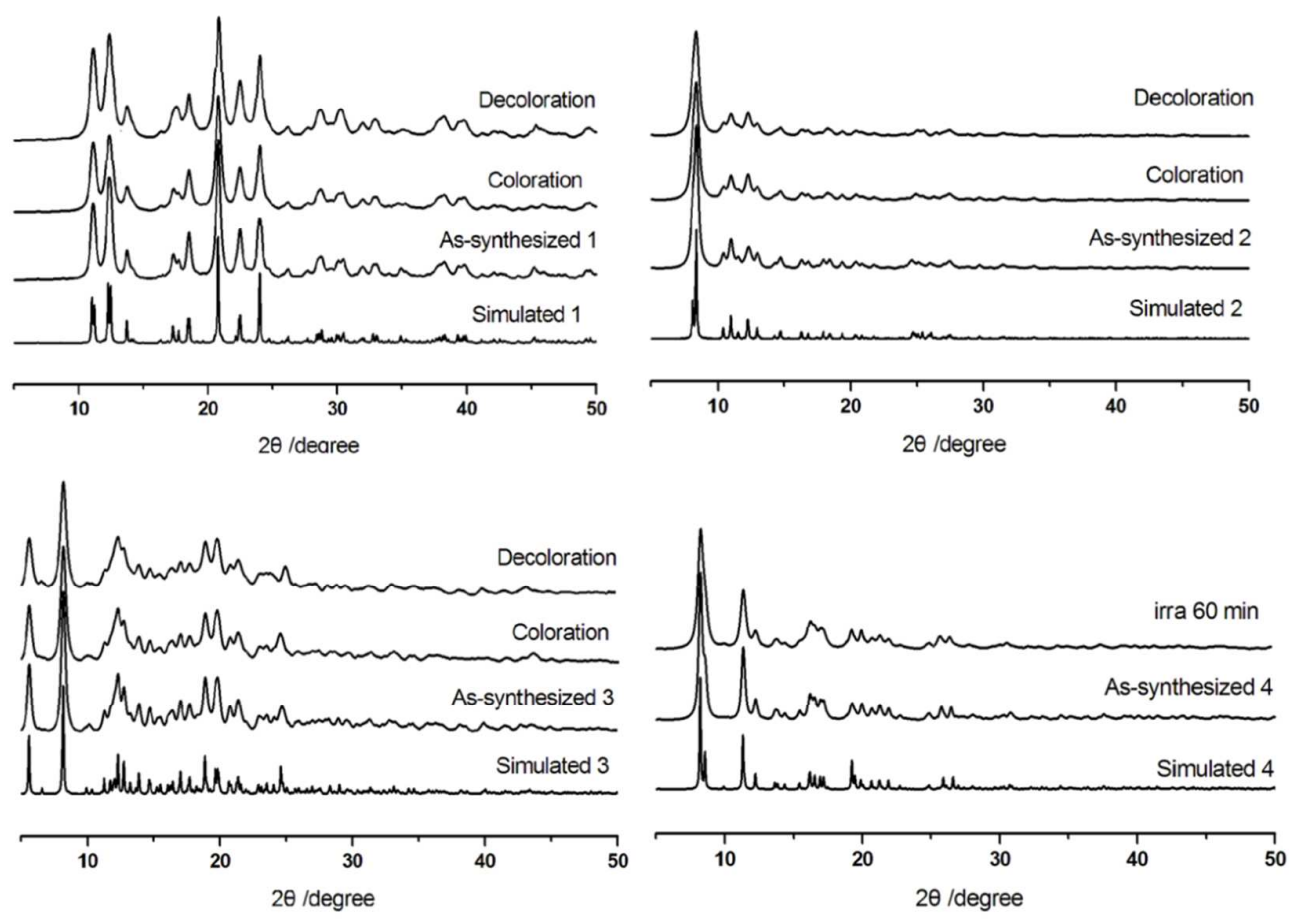

Figure S16. PXRD patterns on the stabilities of crystals 1-4.

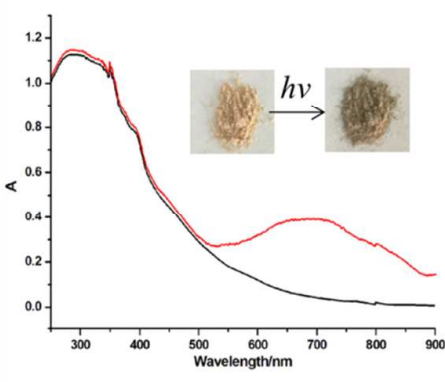

(a)

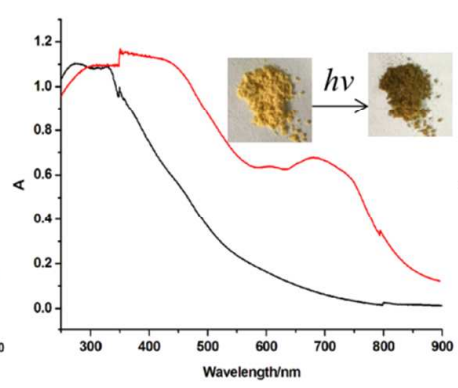

(b)

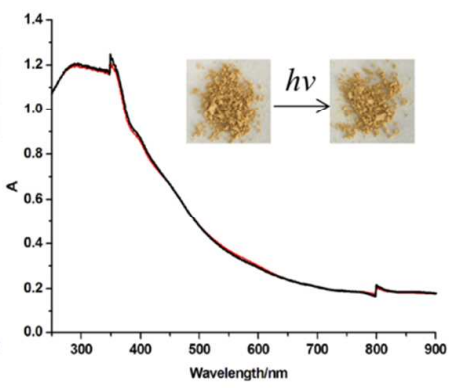

(c)

Figure S17. UV/Vis spectra and photographs showing the photochromic behaviours of (a) $\mathrm{H}_{2} \mathrm{bcbp} \cdot 2 \mathrm{Cl}$, (b) $\mathrm{H}_{2} \mathrm{bcbp} \cdot \mathrm{PFO}_{3}$ and $\mathrm{H}_{2} \mathrm{bcbp} \cdot 2 \mathrm{ClO}_{4}$ (Black line: before irradiation, red line: after irradiation). 


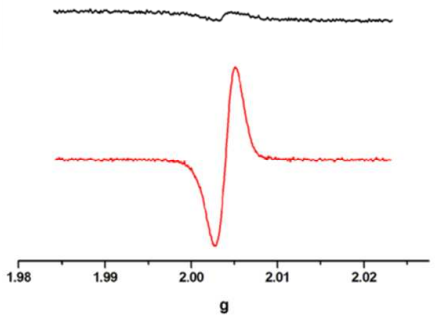

(a)

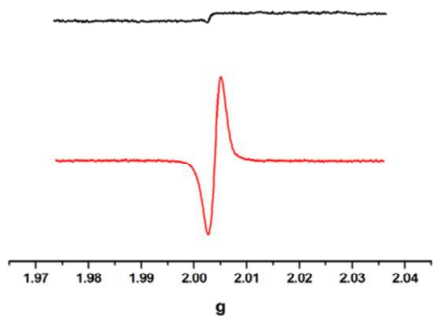

(b)

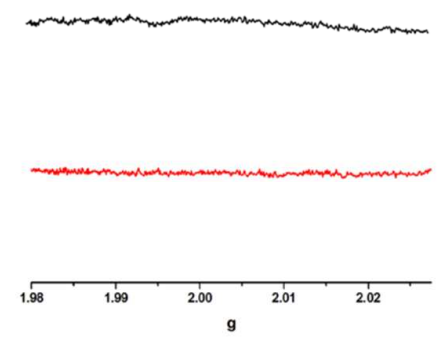

(c)

Figure S18. The ESR spectra of $\mathrm{H}_{2} \mathrm{bcbp} \cdot 2 \mathrm{Cl}(\mathrm{a}), \mathrm{H}_{2} \mathrm{bcbp} \cdot \mathrm{PFO}_{3}(\mathrm{~b})$ and $\mathrm{H}_{2} \mathrm{bcbp} \cdot 2 \mathrm{ClO}_{4}$ (c) in the solid state at room temperature before (black line) and after irradiation (red line). 